\title{
The Core, Support and Integration of News Communication under the New Media Environment
}

\author{
Jiang Ting \\ Liaoning Advertising Vocational College
}

Keywords: media integration; news communication education; innovation cultivation

\begin{abstract}
With the change of times, new media has gradually become the mainstream. With its rapid development, the news communication industry not only has many new propositions, but also embraces more requirements. In the training of talents, news communication education mainly attaches importance to the cultivation of innovative ability and talents who can serve the society. In teaching, it combines theoretical and practical learning to help students to study skills, innovate practice and serve the society.
\end{abstract}

\section{Introduction}

Great changes have taken place in communication technology, which not only bring great changes to the field of news communication, but also cause some problems worthy of deep consideration and discussion. How does news communication education consider these changes? With the constant development of times, the society is making continuous progress. One problem for all educators to ponder is how to cultivate high-tech talents who can meet the needs of society and have adaptability. With the introduction of Internet into our country in 1994, after similar media integration, big data, webcast and other new words into our lives, it is these concepts that we have never heard of that are spreading all over the globe, quietly changing the world bit by bit. Under such a rapid development of the era, the very important news education should discard its dross, abandon some bad habits that can not adapt to the new era, stick to learning experience and the rules that we should abide by under the development of times. Only in this way can we have our own foothold and progress in the constant reform and innovation.

\section{Cultivate Innovation Ability through the Whole Process}

Under the long-term development, the traditional media has its own development pattern and law, and the way of training talents in news communication is basically fixed. The ability cultivation of traditional news education is only applicable under the environment at that time. In some cases, simple mending and step-by-step work are more suitable than other ways. With the emergence of Network and the development and improvement of technology, the quality of talents has changed from one-way communication to two-way communication. But even if the status has changed, the nature has not changed in essence.

Communication of the new media age is carried out in the form of a Network, which makes the concept of "communicators" and "receivers" more confusing. In the traditional sense, it makes this kind of perspective desalinate. In August, 2015, The document entitled "Promote Big Data's Development Program" issued by the State Council states that "the flow of data leads the flow of technology, materials, capital, and talents. It will promote the intensification and innovation of production organization”. All of these will have a profound impact on the future and development of news industry, and news related educators must pay attention to this influence and take appropriate action. “The most prominent aspect of today's media trends is the transformation from singularity to integration, and the best effect of integration is integration. This requires us not to think about problems in a single traditional way, but to adopt the integration method......This kind of thinking should run through teaching practice, dismantle professional boundaries, give up the logic of classifying by media, and set up curriculum based on the necessity not the importance while 
facing the demands of the whole media". Therefore, the core of the work of news communication educators must be innovation.

Compared with the traditional media, the development of new media puts forward higher standards for people involved in the news industry. While meeting these high standards, new media, like traditional media, requires people in related industries to have good qualities.

\subsection{International Perspective}

In 1967, the concept of "global village” was published by famous communicator M. McLuhan. At that time, because of poor technology, economy and so on, it was just a fantasy. However, with the continuous development of science and technology, the economic level continues to improve. Today, in our growing science and technology, we have finally turned fantasy into reality. Therefore, different from the traditional media, the international perspective of new media is very urgent. Moreover, our country's strength of various aspects is gradually strengthened and the comprehensive national strength also unceasingly improves. We are constantly getting closer to the world, so our media should enter the world to compete with other countries for international news. Thus, we can make our voice heard on the world stage. If we really want to make this "voice" sound and loud, the most important thing is to have an international perspective.

\subsection{Professionalism Spirit}

In recent years, the emergence of some negative news and some nonstandard news dissemination have seriously damaged the reputation of news industry. In negative news, I noticed two details. The first is the concentration of anomie behaviors, especially some deliberately fabricated defamatory false news. Second, those who have been in a good reputation and own quality for years also have had some anomie behaviors. The first detail is common in the press. With the development of times, all of us can publish our own ideas and opinions. News professionalism does not only restrict journalists, but also require us who act as communicators. The second detail proposes a more persistent issue in the news industry. Today, new media industry is growing faster and faster. The momentum of this rapid development has made the competition in news industry become increasingly fierce. The traditional media has lost its advantages, which makes some journalists of traditional media have anomie behaviors as a result of a variety of factors. With the development of times, all kinds of temptation are becoming increasingly severe, that makes those journalists with poor psychological quality and control ability have anomie.

\subsection{Social Responsibility Consciousness}

Compared with the past, in the history of press, the present era is the most prosperous and most influential for people's daily life. The most typical phenomenon is those "Phubbers" everywhere now. In the new media age with fast Internet, a message can be quickly spread through software such as QQ, WeChat, Micro-blog all over the country and even the world. A journalist has a huge amount of information every day, so if a journalist has no sense of social responsibility, millions of messages he sends out will cause serious social problems. Therefore, a journalist must have a good sense of social responsibility to ensure that his messages are accurate, not fabricated, and not harmful to society.

\subsection{Modern Communication Skills}

We should master not only modern communication technologies, but also the words and styles used in the dissemination of Network information. Of all the basic requirements, the core and the most important is the individual's ability to innovate, which is also a high-level requirement and standard for journalists. First of all, journalists are mainly concerned about the trivial appearance of social reality and the new media records these social changes. Society is boring and rigid in journalists' works, but colorful and colorful in new media. This requires journalists to change the perspective and inertia of thinking to better transform and express the colorful world. Secondly, the expressions used by traditional news communicators have become increasingly unpopular with the growth of time. Since most people do not like the single way to express information of traditional 
workers, they appreciate the new media style of expression more and more, which seems to be interesting, vivid and precise. As a news communicator, we must adapt to new requirements arising from the changes of times. Therefore, in news communication education, we must not only impart theoretical knowledge in books, but also cultivate the consciousness of innovation, so that students can have unlimited potential.

\section{3. "Never Abandon" the Market and Keep the State of "Neither Close Nor Distant"}

"Never abandon" refers to news dissemination education's respect for the market which is quite essential. First of all, it is the primary goal of higher education to cultivate talents of social need. For news communication education, the employment rate is one of the important manifestations of colleges' high quality, and the key to increase employment rate is that the talents trained are of social need. Only in this way will it be accepted by the public. News communication discipline has the feature of strong practice. Every move of media field and all kinds of changes will cause a great sensation or change. In addition, the demand of market will change a lot at any time and a great change will take place without being careful. Therefore, we must practice the practicality of news communication, pay more attention to the every move of media and observe the change of market demand.

This concept can also bring people who study the subject closer to the market, increase their sensitivity to market demand and let them learn from each other in the process of practice. Teachers of higher education are also able to change the contents and methods of teaching through the market' changes and the development of society. However, we should keep "neither close nor distant" before "never abandon" the market, that is, to keep close but not to pander at the same time, maintaining a relatively stable and safe distance. The reason is that the market always has small big or small, obvious or not clear changes at all times, but people do not vary from minute to minute. Facing those changes, people generally need time to change to clear the new educational ideas and methods. As a result, we can neither catch up with the changing pace of the market, nor have to keep up with this rapid change since the result can only be futile. Therefore, we draw a conclusion that higher education should be rational and independent.

\section{Combine Support, Theoretical Education with Practical Experience}

In theoretical teaching, the first thing we should do is to improve the connotation of students and to adopt targeted teaching methods. In practice teaching, we also need to pay attention to master theories and to keep up with practice. We should realize that to be in its position and to seek good things.

\section{Trinity: Skills Learning, Innovative Training and Social Service}

In skills learning, we should attach importance to the strength of a team. In a team, students are capable of learning by giving full play of their special skills, and even some teams can be equipped with guiding teachers. So, forming a team is really a very meaningful thing. In our daily media news work, team is inseparable. For example, when disseminate visual news and collect big data news, it is necessary to complete a colorful and infectious report with the help of text reporters and data miner. Therefore, journalists' sense of solidarity and cooperation should be cultivated when they receive higher education. In terms of the direction of news communication, educators are linked together, and higher education courses are integrated. However, it is this kind of link and integration that will produce even better journalists. At the same time, it is necessary to cultivate students' ability of innovation and independent thinking. Innovative training aims to enable students to accept the ability to change among multiple identities, such as journalist, writer, and commentator. The ability of a journalist is to find news in ordinary society and to focus on the key of what happens suddenly. Writers' ability lies in the ability to describe events and to link fragmentation into scenes by description. Commentators' ability is mainly to achieve the pertinence of event, keeping 
away from extreme and network violence. We should also cultivate students' noble news ideas, build a fair and just picture by cleaning ourselves and keep free from all kinds of temptations. Besides, we need to be enthusiastic about the public interest and offer practice. On the road of realizing the ideal dream of journalism, we should start from the concrete practice and cultivate a strong sense of commonweal, the sense of social people and the sense of responsibility.

\section{Conclusion}

With the development of new era, new media will gradually become the most acceptable way to spread information. The development of new media takes innovation ability as the core, cultivate various qualities, make the combination of theory and practice as the support, realize the core, support and integration of new media in the news dissemination field by integrating learning skills, innovative training and community time. I believe that with the times' change, new media will become more powerful and news communication education will cultivate new generations of journalists who can serve our country.

\section{References}

[1] Gu Liping. The Core, Support and Integration of News Communication Education under New Media Environment [J]. Modern Communication (Journal of Communication University of China), 2016,38(08):141-144.

[2] Hu Yu, Zhang Jinbao. High Quality Contents in New Media Dissemination: Production and Evaluation [J]. Young Journalist, 2018 (04): 11-13.

[3] Zhang Xiaomin. Innovation Path of Mainstream Paper Media Conference Report under the Environment of Melting Media-Taking the 18th National Congress and 19th CPC National Congress Reports of “People’s Daily” as an Example [J]. Modern Audio-visual: 2018: 22: 16-20.

[4] Zhong Kexun.The Core Value in the Transformation of News Communication [J]. Journal of Southwest University for Nationalities (Humanities and Social Sciences Edition): 2015, 36 (06): 158-163.

[5] Hu Decai. The Idea and Path of Talents Training of News Communication in the Era of Media Integration Age [J]. University of Journalism: 2015 (05): 119-125.

[6] Nan Changsen, Bai Xia. Integration Development, Comprehensive Innovation: A Review of the Development of News Communication Subject in 2016 [J]. Journal of Changan University (Social Science Edition): 2017,19(01):106-124. 